\title{
Relationships between the Maritime Continent Heat Source and the El Niño-Southern Oscillation Phenomenon
}

\author{
John L. McBride, Malcolm R. Haylock, And Neville Nicholls \\ Bureau of Meteorology Research Centre, Melbourne, Australia
}

(Manuscript received 26 November 2001, in final form 16 January 2003)

\begin{abstract}
Various earlier studies have demonstrated that rainfall in the Maritime Continent-Indonesia region is strongly related to the El Niño-Southern Oscillation (ENSO) during the dry half of the year but has a very weak association with ENSO during the summer-wet season months. This relationship is investigated over a wider domain through the use of outgoing longwave radiation (OLR) data as a proxy for rainfall.

Consistent with the hypothesis of Haylock and McBride, it is found that the large-scale structure of the loworder empirical orthogonal functions (EOFs) of OLR have a strong resemblance to the patterns of correlation between OLR and the Southern Oscillation index (SOI). This supports the hypothesis that the predictable component of rainfall is determined by the component that is spatially coherent, as quantified through EOF analysis.

As was found earlier with rainfall, the region of largest correlation between interannual OLR anomalies and the SOI lies in the winter hemisphere. The predictable component of OLR (or rainfall) remains in the region of the Maritime Continent throughout the year and thus does not accompany the minimum OLR (maximum rainfall) during its annual interhemispheric progression as the major monsoon heat source.

The sign of the OLR-SOI relationship is such that the Maritime Continent has increased rainfall during a La Niña or cold event. Patterns of correlation between sea surface temperature and the SOI show the existence of a region to the east of the Maritime Continent whereby sea surface temperature anomalies are positive during these (La Niña) conditions. This is in the sense of a direct relationship, that is, positive sea surface temperature anomalies corresponding to increased rainfall.

The annual cycle of the sea surface temperature structure of ENSO is represented by the first EOF of the interannual sea surface temperature series for each separate calendar month. The region of the sea surface temperature anomaly giving the direct relationship with Maritime Continent rainfall is part of the "boomerangshaped" pattern that lies between and has the opposite sign from the anomalies in the eastern-central Pacific and the Indian Oceans. Besides being a fundamental component of the large-scale sea surface temperature structure of ENSO, the boomerang pattern goes through an annual cycle such that it has maximum amplitude in the winter hemisphere. This suggests that interannual variations of Maritime Continent rainfall are in direct response to upstream sea surface temperature anomalies in the ENSO boomerang pattern.
\end{abstract}

\section{Introduction}

The El Niño-Southern Oscillation (ENSO) phenomenon is a major controlling factor of interannual variability of climate over the globe. A fundamental component of this coupled atmosphere-ocean phenomenon is the variability of equatorial convective rainfall in the west-central Pacific, at approximately the longitude of the date line. On interannual timescales the magnitude of convective activity at this location is both a response to variations in the underlying sea surface temperatures (SSTs) as well as a driving force for the trade winds across the eastern Pacific, through the mechanisms elucidated by Gill (1980), Webster (1981), and Zebiak

Corresponding author address: Dr. John L. McBride, Bureau of Meteorology Research Centre, GPO Box 1289K, Melbourne 3001, Australia.

E-mail: J.Mcbride@bom.gov.au
(1982). In recent years there have also been considerable advances in the understanding of the relationships between ENSO variations and variations in convective activity associated with the Northern Hemisphere branch of the Asian monsoon (see, e.g., Kirtman and Shukla 2000; Lawrence and Webster 2001; Lau and Wu 2001).

The current paper addresses variability of convection and rainfall in a third tropical heat source: in the intervening longitudes of Australia and the Maritime Continent. As discussed by Lau and Chan (1983b), Meehl (1987), and McBride (1998), Maritime Continent convection and northern summer monsoon convection can be both considered part of the planetary monsoon system, with the tropical convective maximum undergoing an annual migration from over northern India in July to Indonesia in November-December (Meehl 1987).

The relationship between Maritime Continent convection and ENSO has been previously studied by Lau 
and Chan (1983a,b). These authors documented the existence of a dipole in convective variation between the Maritime Continent and the date line. Thus, during a warm event convection is enhanced over the date line and depressed over the Maritime Continent, with the converse happening during a cold event. The association between ENSO and interannual variations in Maritime Continent convection has the sense that low pressure is associated with high rainfall. Thus, Maritime Continent rainfall is greater than normal during a cold event when the Jakarta, Indonesia, or Darwin, Australia, pressure anomaly is negative and less than normal in the opposite (warm) phase when Jakarta has a positive pressure anomaly.

It has long been known there is a strong seasonal variation in the association between Australian-Indonesian rainfall and the Southern Oscillation (Nicholls 1981; McBride and Nicholls 1983; Hastenrath 1987; Ropelewski and Halpert 1987; Kiladis and Diaz 1989; Kirono et al. 1999). Using monthly rainfall from 63 stations across Indonesia, Haylock and McBride (2001) demonstrated that rainfall in the dry and transition seasons is highly correlated with ENSO; whereas in the wet season of December-January there is little or no correlation. They used empirical orthogonal function (EOF) analysis to demonstrate that interannual variations in wet season rainfall exhibit very little spatial coherence. Haylock and McBride hypothesised that predictability of rainfall in a region is dependent on coherence of the rainfall anomalies. On this basis they concluded that Maritime Continent wet season rainfall is inherently unpredictable.

The current note documents further exploration of the seasonal structure of ENSO-monsoon rainfall relationships. Through the use of outgoing longwave radiation (OLR) as a proxy for convection, the relationships have been extended beyond the land points represented by the Haylock-McBride station network. The data used in the paper are OLR data for the period 1974-2001 (excluding 1978), from the National Oceanic and Atmospheric Administration (NOAA) polar-orbiting satellites as described by Gruber and Krueger (1984). Gridded SST data for the period 1949-98 are from the Met Office Global Sea Ice and Sea Surface Temperature dataset (GISST; Parker et al. 1995). The index of ENSO activity used is the Southern Oscillation index (SOI), which is the normalized Tahiti-minus-Darwin pressure difference as described by Allan et al. (1991). In section 2 the results of EOF analyses are shown for each calendar month for both OLR and SST. These are related to the spatial structure of the relationships between OLR variability and ENSO. Section 3 summarizes and discusses these results.

The focus of the study is on ENSO-OLR relationships specifically in the Maritime Continent. This is as a follow-up to our earlier study. It is also because interannual variability of Maritime Continent convection could play an important part in global dynamics. For example the studies of Simmons et al. (1983) and Ting and Sardeshmukh (1993) demonstrate that atmospheric teleconnection patterns and extratropical responses to tropical heat anomalies are highly sensitive to the longitudes at which the heating anomalies occur. Thus, it is important to understand the ENSO response of the major equatorial rainfall centers.

The main finding is that the phenomenon of the dry season being related to ENSO and the wet season being effectively independent of ENSO is a general result extending beyond the island station network to cover the entire region. Examination of the annual cycle of the west Pacific SST pattern associated with ENSO reveals the existence of a related phenomenon in SST. Specifically, Maritime Continent rainfall seems to be controlled by fluctuations in a "boomerang-shaped" SST anomaly pattern of opposite sign to the anomalies in the equatorial eastern Pacific. Considering the relationship between coherence and predictability proposed by Haylock and McBride, the predictable component of monsoon convective activity is not in the major heat source of the planetary monsoon, but rather in the Maritime Continent region and centered in the winter hemisphere. This has implications for understanding the interactions between ENSO and the planetary monsoon.

\section{Analysis}

\section{a. Correspondence between coherence and predictability}

Haylock and McBride (2001), through their analysis of Indonesian monthly station data, demonstrated a close correspondence between regions showing large amplitude in the low-order EOFs and regions that are simultaneously correlated with the SOI. To extend this beyond the station network, which is restricted to the islands of Indonesia, we use OLR as a proxy for rainfall, following the reasoning of Heddinghaus and Krueger (1981).

Figure 1 shows the first unrotated EOF of the correlation matrix of OLR for the four calendar months of January, April, July, and October over the region $50^{\circ} \mathrm{S}-$ $30^{\circ} \mathrm{N}$ and $70^{\circ} \mathrm{E}-180^{\circ}$. The variance explained by the first EOF for the four months is $18.4 \%, 18.8 \%, 15.5 \%$, and $20.7 \%$, respectively. The figures show the spatial patterns of the loadings for each EOF, with light and dark shading representing loadings of opposite sign. Regions where there are large amplitudes in the EOF pattern signify regions where the interannual anomalies for that month are highly correlated with the amplitude of that EOF. Accordingly, the data points within these regions have anomaly time series that are coherent with each other.

For all 4 times of the year there is a dipole structure in this first EOF with a large structure of one sign (light shading) over the Maritime Continent and Indochina longitudes and a structure of opposite sign (dark shad- 

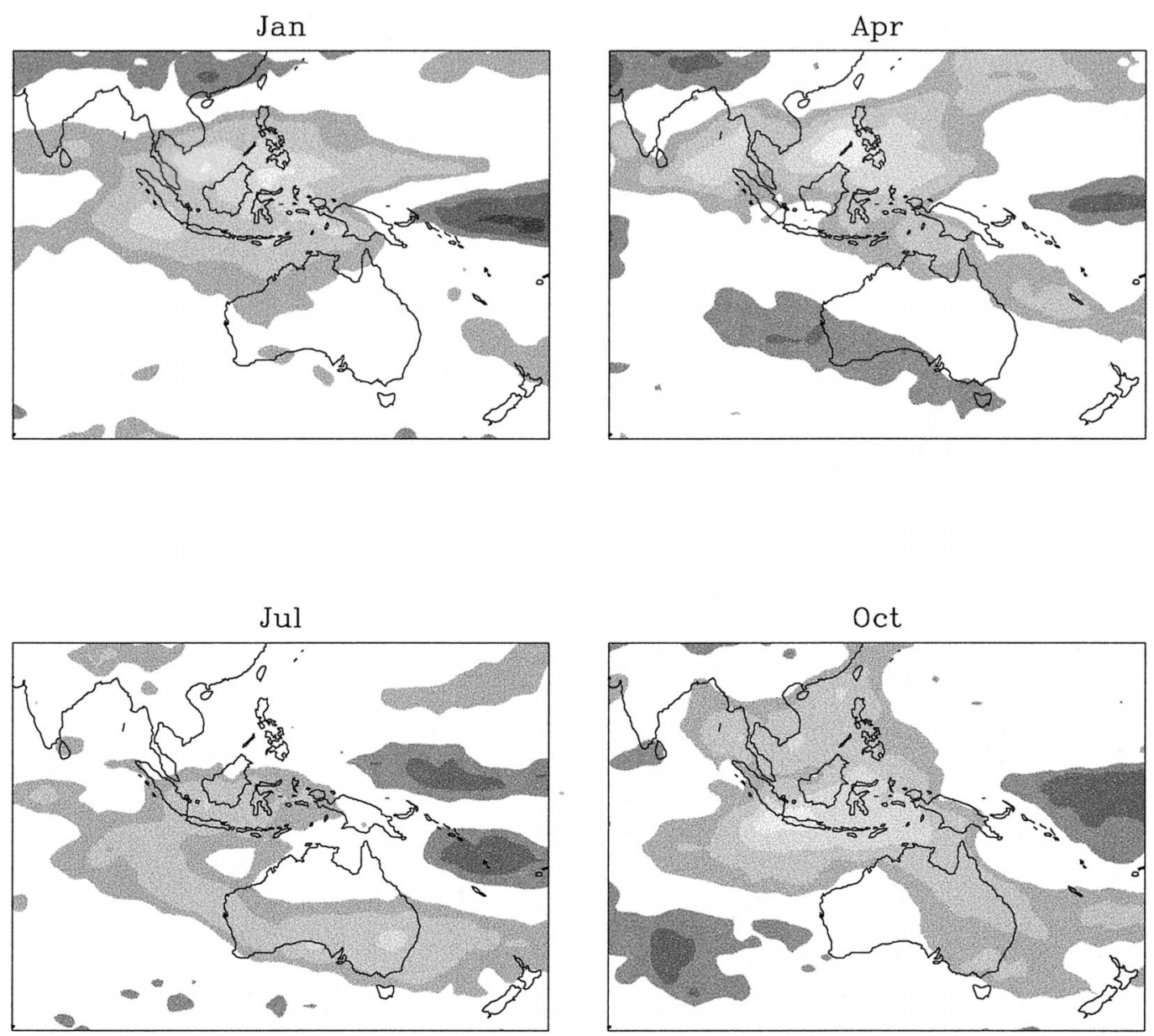

FIG. 1. Spatial patterns of loadings for the first unrotated principal components of the interannual time series of OLR for individual calendar months. The four panels are for the months of Jan, Apr, Jul, and Oct, as labeled. Loadings with magnitude greater than 0.4 are shaded, with shading intervals of 0.2 . Dark shading and light shading represent loadings of opposite (arbitrary) sign.

ing) over the equatorial Tropics in the eastern part of the domain. As discussed in the introduction, the two centers of the dipole are described here as being the Maritime Continent convection and the date line convection, respectively. There are also a number of bands of structure of either sign extending from the equator toward the northeast and toward the southeast at various times of the year.

The four panels of Fig. 2 show the correlations between OLR and the SOI over the same period (19742001) for the same calendar months. The remarkable characteristic of these four diagrams is the similarity of structure to the corresponding panel in Fig. 1. For example, in January the lowest-order EOF (Fig. 1) has the largest amplitude over northern Borneo and the southern Philippines with a tongue of amplitude of the same sign extending eastward. The same structure shows up in the corresponding correlation map in Fig. 2. In July the Maritime Continent branch of the dipole is a relatively small region located over southern Borneo and Java, while the date line branch spans a wide latitude range and extends westward almost to New Guinea. Once again the same features show up in the correlation pattern.

According to the Haylock-McBride hypothesis, predictability for a large-scale domain requires spatial coherence over that domain, and that coherence can be quantified as having large amplitude in the low-order EOFs. It would be expected that the predictable component of the signal would be the same component that is correlated with indices of large-scale phenomena, such as the SOI. The close similarity between the patterns in each panel of Fig. 2 and the patterns in the corresponding panel of Fig. 1 provides support for the Haylock-McBride hypothesis.

There are some interesting differences between the (OLR-SOI) correlation patterns in Fig. 2 and the corresponding (rainfall-SOI) correlations in Haylock and McBride (2001) and in Kirono et al. (1999). Specifically, the correlation patterns for OLR are smoother and have larger-scale structures. This may reflect the fact that OLR is on a regular grid of relatively coarse $\left(2.5^{\circ}\right)$ 

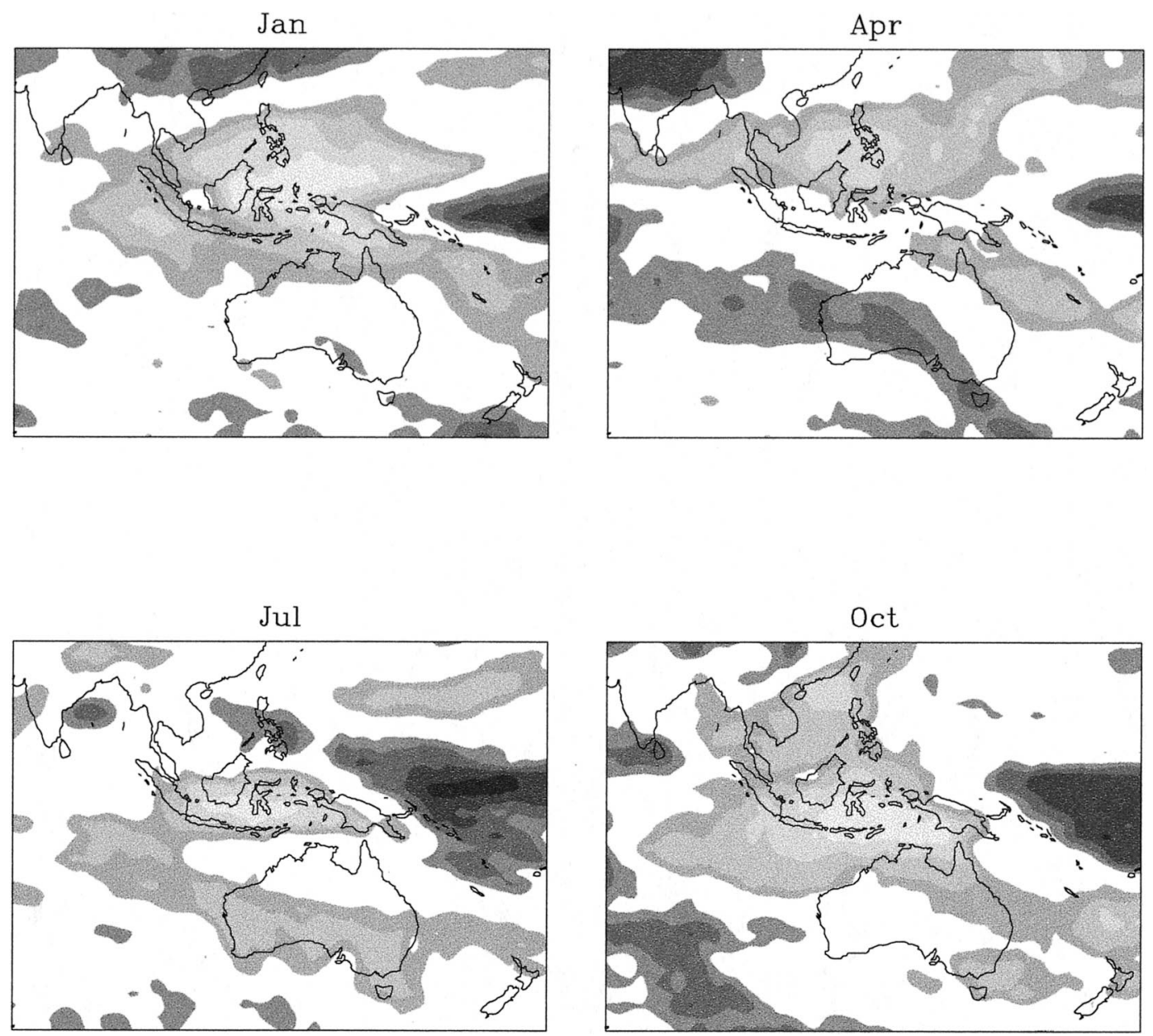

FIG. 2. Coefficients of linear correlation between OLR and the SOI for the interannual time series of individual calendar months. Shading is for correlations of magnitude greater than 0.3 , with shading intervals of 0.15 . Light shading represents negative correlations (i.e., dry in an El Niño or warm event) while dark shading represents positive correlations.

resolution. It also may be related to physical differences whereby OLR is more spatially coherent than rainfall. Despite that, the key point remains that for either variable (OLR or rainfall) the lowest-order EOF bears a strong structural similarity to the pattern of correlation between that variable and the SOI.

\section{b. Predictability located in the winter hemisphere of the Maritime Continent}

As has been described by Heddinghaus and Krueger (1981), Lau and Chan (1983b), and others, the major region of convective activity associated with the planetary monsoon undergoes a seasonal variation such that in the northern summer it is located in the Northern Hemisphere with the maximum activity over the Bay of Bengal-India-Indochina region. In the southern summer it is located in the Southern Hemisphere with maximum activity over southern Indonesia and Papua New Guinea.

In contrast to this, Fig. 1 indicates that the region of
OLR with coherent anomalies remains over the Maritime Continent; that is, it does not follow the annual return excursion from the Maritime Continent to IndiaIndochina. As discussed above and proposed by Haylock and McBride (2001) the coherent part of the OLR anomaly is related to that component that is predictable. Using the magnitude of the linear correlation coefficient with the SOI as a simple measure of predictability, the seasonal cycle of the total signal and also of its predictable component (maximum convection, predictable convection) is shown in Fig. 3. For each month the maximum convection is represented by the shaded area, which denotes OLR values less than $220 \mathrm{~W} \mathrm{~m}^{-2}$ in the long-term monthly mean. The predictable convection is represented by the hatched area that denotes locations where that month's anomalies of OLR are negatively correlated with the SOI at magnitudes greater than 0.6.

A noteworthy aspect of the annual cycle of the region with large magnitude (OLR-SOI) correlations is that it is generally located in the winter hemisphere. Thus, during January-April it is located north of the equator; and 

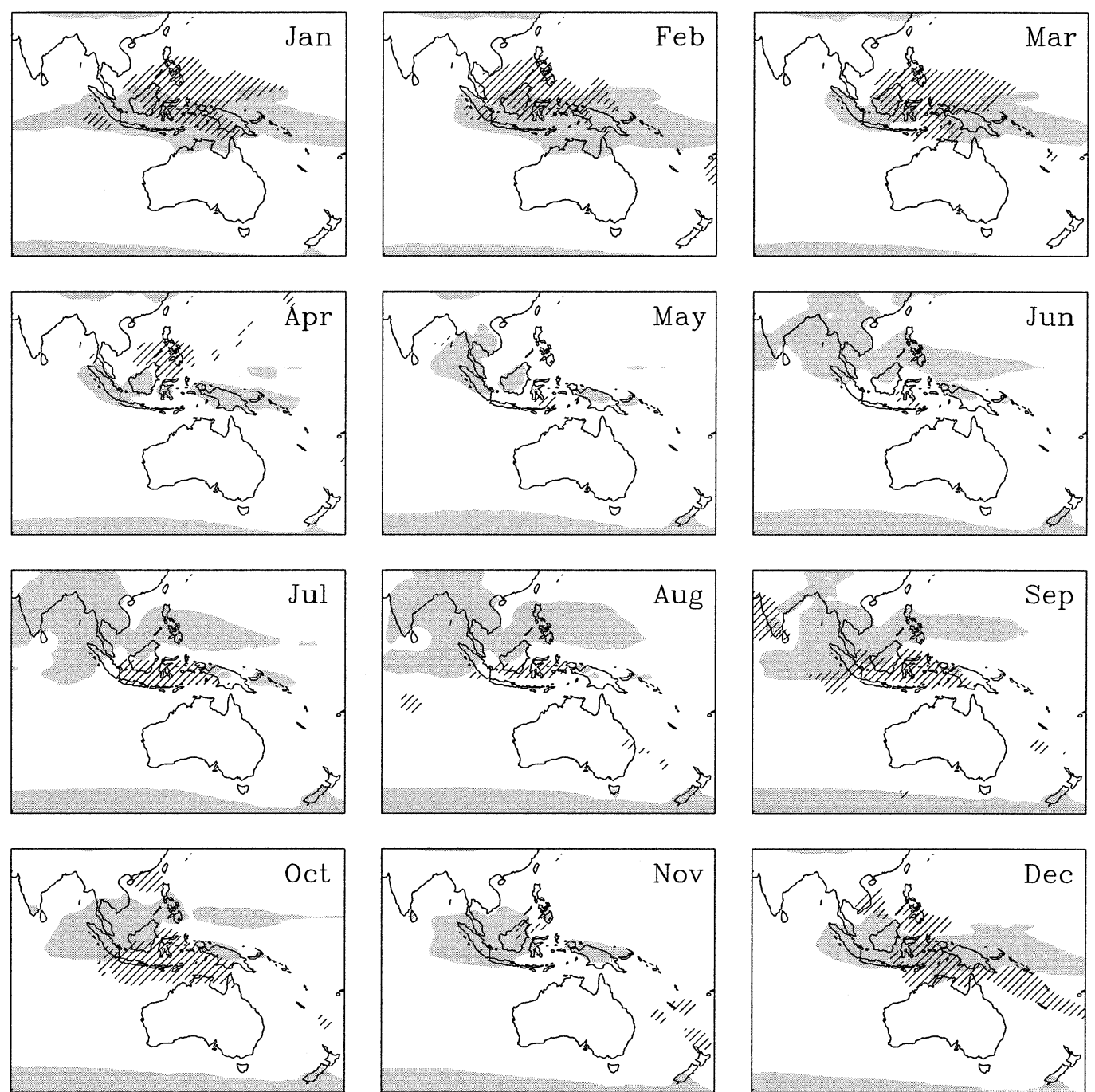

FIG. 3. The annual cycle of cold cloud over the Maritime Continent as represented by the presence of low values of OLR: the shaded area for each month being long-term mean OLR values less than $220 \mathrm{~W} \mathrm{~m}^{-2}$. Superimposed for each month is the area of OLR that is negatively correlated with the SOI, with the hatching representing correlations of magnitude greater than 0.6 .

in July-October it is located south of the equator. This is consistent with the findings of Haylock and McBride (2001) that rainfall over most of their Indonesian station network is predictable in June-November, but only in the north of their region in December-February and nowhere during March-May. The Haylock-McBride station network lies mainly in the more populated parts of Indonesia (Java, Nusa Tenggara), which are south of the equator, with a few stations in the Northern Hemisphere.

\section{c. The boomerang pattern in sea surface temperature anomalies}

Figures 2 and 3 reveal a strong seasonal cycle in the location and magnitude of correlations between OLR and the SOI; and as shown in Fig. 3 this seasonal struc- ture is not related in any simple way to the seasonal evolution of the OLR itself. This immediately raises the question as to how it is related to the seasonal evolution of the ENSO phenomenon.

Figure 4 shows maps of correlation between sea surface temperature and the SOI for the three southern summer months of January-March. Also shown (cross hatching) is the region of predictable OLR for each month (as represented by negative OLR-SOI correlations of magnitude greater than 0.6). The light shading is for positive correlation; dark is for negative. There is dark shading through the islands of the Maritime Continent and westward into the Indian Ocean, signifying that when the SOI is positive (i.e., during a La Niña event), sea surface temperatures throughout the Maritime Continent are cold. There is a region of (SST-SOI) correlation of the opposite sign (light shading) located 

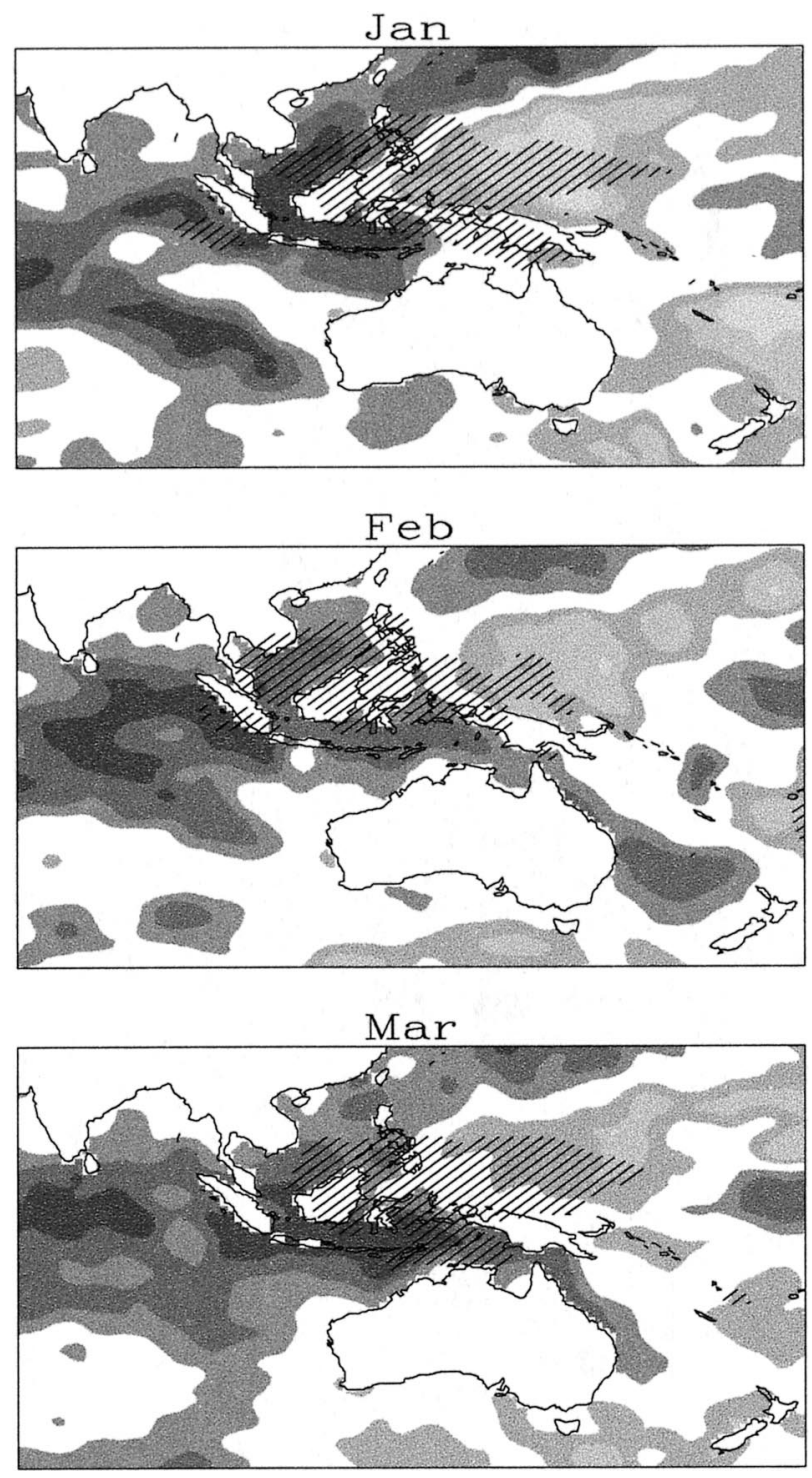

FIG. 4. Coefficients of linear correlation between SST and the SOI for the interannual time series of individual calendar months. Results are shown for the three southern summer months of Jan-Mar. Shading is for correlations of magnitude greater than 0.2 , with shading intervals of 0.2. Dark shading is for negative correlations; light shading for positive. Also shown (hatching) is the region where OLR is negatively correlated with the SOI, with the hatching representing correlations of magnitude greater than 0.6.

north of the equator and extending northeast from the hatched region of high-magnitude (SOI-OLR) correlation. This light-shaded region is of the sign such that during a La Niña, when rainfall is enhanced over the northern (winter hemisphere) portion of the Maritime Continent, the sea surface temperatures are warm. In these months (January-March) this region is collocated with the winter northeasterly trade winds. Thus in a La Niña/cold event the warm sea surface temperatures are upstream of the region where the Maritime Continent convection is enhanced.
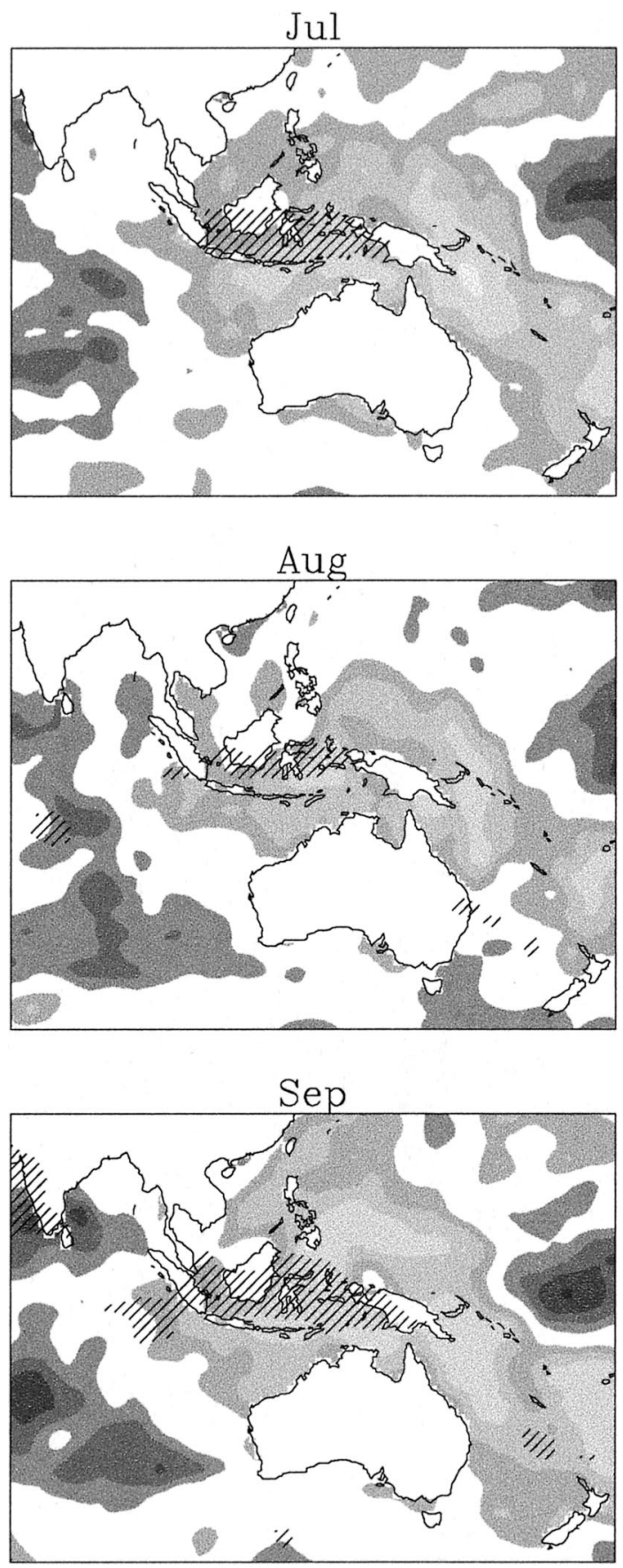

FIG. 5. Same as Fig. 4, but for the months of Jul-Aug-Sep.

Figure 5 shows the equivalent figure for the time of year when the "predictable" component of convection lies over the Southern Hemisphere part of the Maritime Continent, that is, July-September. At this time of year there is light shading (positive correlations) throughout the Maritime Continent signifying positive sea surface temperatures during a La Niña. Here the positive correlations span both sides of the equator; but as with the previous figure the correlation pattern extends eastward 

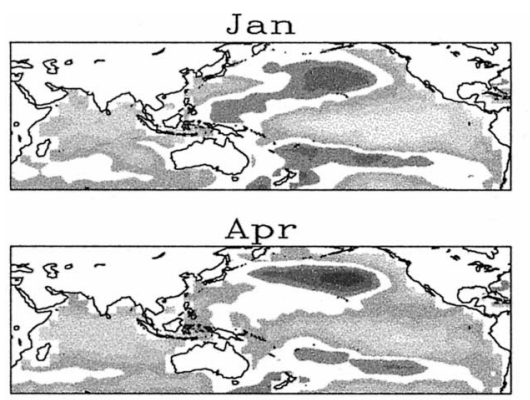

Jul

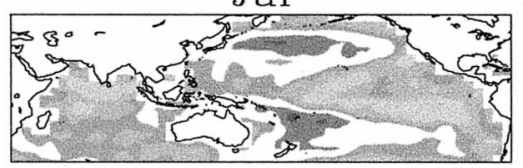

Oct

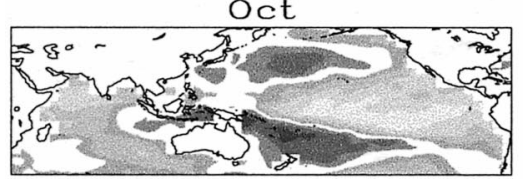

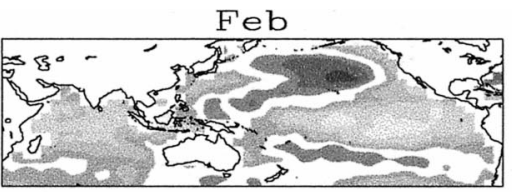

May

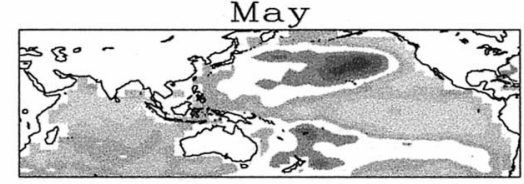

Aug

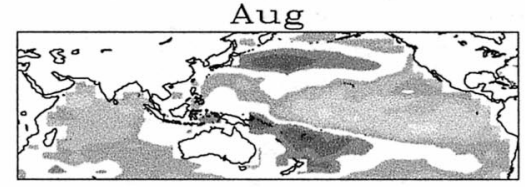

Nov

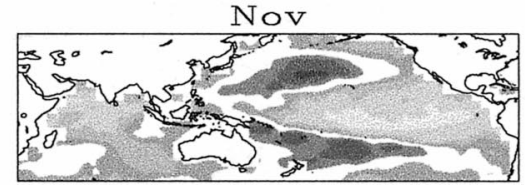

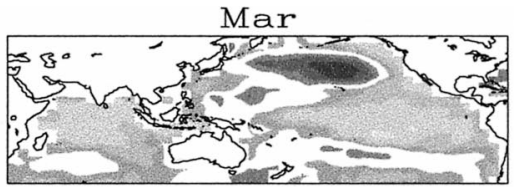

Jun

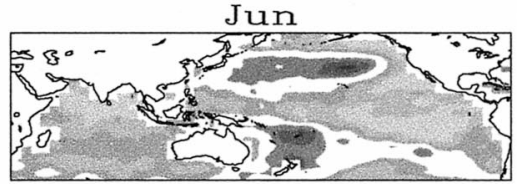

Sep
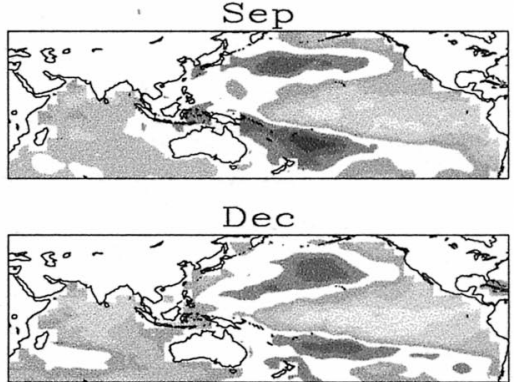

FIG. 6. Spatial patterns of loadings for the first unrotated principal components (using the correlation matrix) of the interannual time series of SST for individual calendar months. Light and dark shadings represent loadings of opposite sign. Shading is for loading magnitudes greater than 0.2 , with intervals of 0.2 .

and poleward (in this case southward) following the path of the winter trade winds.

\section{d. The seasonal cycle of the ENSO SST anomaly pattern}

The seasonal variation of the correlations between the SOI and sea surface temperature in Figs. 4 and 5 can be interpreted as a depiction of the seasonal structure, for this sector, of the sea surface temperature pattern for ENSO. A number of previous authors have represented the ENSO sea surface temperature pattern through the use of EOF analysis of sea surface temperatures from the Pacific Ocean (Weare et al. 1976), combined IndianPacific Oceans (Drosdowsky and Chambers 2001), or the globe (Hsiung and Newell 1983). In these studies the seasonal cycle was removed through the analysis of a time series of monthly anomalies, where in each case the anomaly was formed by subtracting the mean for that calendar month. For each of the above studies the first EOF of sea surface temperature was associated with the ENSO phenomenon, and accounted for $23.1 \%$ of the variance for the Pacific, $14.9 \%$ for the Pacific-Indian Oceans, and $7.7 \%$ for the globe.

Based on the above studies, we can identify the largescale sea surface temperature structure of ENSO with the first nonseasonal EOF of Pacific-Indian Ocean sea surface temperatures. To document the seasonal structure of this EOF, but with the mean seasonal cycle still removed, we have carried out separate EOF analyses of the correlation matrix of Indian-Pacific Ocean sea surface temperatures for each calendar month. The struc- tural maps (weights) for the resultant first EOF are shown in Fig. 6. This figure can be considered to be a representation of the seasonal cycle of the ENSO sea surface temperature pattern. The percentage of variance explained by the pattern varies from a minimum of $15.1 \%$ in August series to a maximum of $20.4 \%$ for October. The interannual correlations between the amplitude of this EOF and the SOI are, respectively, for the 12 months: $-0.71,-079,-071,-0.69,-0.44$, $-0.51,-0.41,-0.72,-0.73,-0.85,-0.65,-0.70$. The correlations with Niño-3.4 $\left(5^{\circ} \mathrm{N}-5^{\circ} \mathrm{S}, 170^{\circ}-120^{\circ} \mathrm{W}\right)$ index are as follows: $0.86,0.84,0.77,0.70,0.76,0.64$, $0.54,0.72,0.83,0.84,0.83,0.83$.

The most familiar feature of the figure is the wedgeshaped pattern in the eastern equatorial Pacific, with a broad pattern of the same sign over the equatorial Indian Ocean. The eastern Pacific anomaly has its maximum amplitude in December-January and minimum in April-June, as is well known (Rasmusson and Carpenter 1982). The other important feature is the boomerangshaped anomaly in the western Pacific that has the opposite sign to the eastern Pacific anomaly. It is present all year and has two zones of maximum amplitude: in the North Pacific during January-May; and in the southwest Pacific during August-November. The regions of positive correlation between the SOI and sea surface temperature shown in Figs. 4 and 5 and discussed in the previous section are part of this boomerang anomaly pattern. As discussed above this anomaly pattern extends poleward and eastward from the Maritime Continent convection and has maximum amplitude in the winter hemisphere. 
The evolution through the year of the boomerang pattern has a number of interesting characteristics. During April-June, the boomerang has a weak structure with the main amplitude in the northern branch but little connection to the equator. In fact, at this time of year the eastern Pacific anomaly extends into the Maritime Continent and connects with the anomaly of the same sign in the Indian Ocean. From July onward, the southern branch of the boomerang builds in magnitude and "curls" around northern Australia, and in SeptemberOctober actually extends through the Maritime Continent into the tropical western Indian Ocean. At the same time the anomaly of the opposite sign in the Indian Ocean retreats westward giving a "dipole structure" to the Indian Ocean ENSO signal, similar to that observed for these months by Saji et al. (1999) and Webster et al. (1999). During December-January the Southern Hemisphere branch of the boomerang weakens and retreats toward the southeast, while simultaneously, the Northern Hemisphere arm increases in magnitude.

\section{e. The mechanisms by which the Southern Oscillation influences Maritime Continent rainfall}

The motivation for this study was primarily to investigate why in the Southern Hemisphere parts of the Maritime Continent the SOI-rainfall relationship is strong during the winter dry season (June-November) but weak during the wet season. From the above analysis, the boomerang pattern is clearly a basic component of the sea surface signal associated with ENSO; and it has the same seasonal behavior, namely, the anomalies are large in the winter hemisphere and weak in the summer hemisphere.

Given the existence of equatorward and westward atmospheric winter trade wind flow, the boomerang sea surface temperature anomalies are located directly upstream of the location of the Maritime Continent convection anomalies. Thus, it is possible that the interannual variability of Maritime Continent convection is simply a downstream response to the boomerang sea surface temperature pattern, which appears to be part of the large-scale structure of ENSO. Thus, during an E1 Niño, SSTs are lower than normal in the boomerang region, the winter trades receive less water vapor through evaporation from the underlying seas, and so the water vapor supply for rainfall over the winter hemisphere portion of the Maritime Continent is decreased. Conversely, during a La Niña, the boomerang is warm, evaporation is increased in the winter trades, and rainfall is increased downstream over Indonesia.

The overall ENSO pattern has an east-west plus-minus-plus structure, corresponding to the Indian Ocean (plus), the Maritime Continent (minus), and the eastcentral Pacific (plus) regions, respectively. It is well documented (e.g., Rasmusson and Carpenter 1982) that convection in the eastern pole of the pattern responds directly to sea surface temperature. If the previous downstream hypothesis is correct, then the same direct relationship applies in the central region of the pattern, that is, the Maritime Continent.

In the western (i.e., Indian Ocean) pole this is not the case. In the Indian monsoon a warm event corresponds to decreased rain; that is, the (rainfall-SOI) relationship has the same sign as for the Maritime Continent; yet as India lies in the western pole of the sea surface temperature pattern, the local (and immediate upstream) sea surface temperature anomalies have the opposite sign. Thus, the mechanisms governing ENSO-monsoon relationships there are different and presumably involve remote forcing from the east Pacific through atmospheric teleconnections, as proposed in the "atmospheric bridge" hypothesis of Lau and Nath (1996) and Klein et al. (1999).

It is important to note that the direct downstream mechanism is purely a hypothesis at this stage. The more traditional mechanism invoked for the response of the Maritime Continent to a warm or cold event has been a direct Walker cell forcing associated with the dipole behavior of Maritime Continent and date line convection. Thus, in a warm event the date line convection is enhanced and the Maritime Continent is suppressed, the mechanism being through direct longitudinal (Walker) circulation (see, e.g., Lau and Chan 1983a,b).

The fact that the boomerang pattern is part of ENSO and has the seasonal structure of a winter hemisphere maximum is beyond doubt. Substantiation can be found in the warm event (El Niño) composites carried out by Rasmusson and Carpenter (1982). The region of negative sea surface temperature anomalies emanating from the Maritime Continent and extending eastward and poleward in the winter hemisphere can be clearly seen in their composites for the southern winter (upper panel of Rasmusson-Carpenter's Fig. 20) and for the northern winter (upper panel of Rasmusson-Carpenter's Fig. 21). During July-October when the southern branch of the boomerang extends through the southern part of the Maritime Continent, the OLR in this region is spatially coherent and strongly correlated with ENSO. Conversely when the northern branch extends into the region during January-April, the OLR in the northern part of the Maritime Continent is spatially coherent and strongly correlated with ENSO.

\section{Summary and discussion}

The major results of this analysis can be summarized as follows:

1) Haylock and McBride's hypothesis that predictability is associated with spatial coherence has been extended from station rainfall to large-scale OLR patterns. The strong resemblance between the structure of the first EOF of OLR (Fig. 1) and the patterns of correlation between OLR and the SOI (Fig. 2) lend strong support to this hypothesis. 
2) The predictable component of the OLR (as specified by the component with a large correlation with the SOI) does not follow the annual march of the major monsoon heat source. Rather it stays in the Maritime Continent region, but in the winter hemisphere. This extends to a much larger region the findings of earlier authors (Nicholls 1981; Hastenrath 1987; Haylock and McBride 2001) that Indonesian rainfall is strongly associated with ENSO in the winter-spring dry season, but not in the summer-autumn wet season.

3) Patterns of correlation coefficients between sea surface temperature and the SOI show a region of correlation of the correct sign for a direct relationship between sea surface temperature anomalies and rainfall. This region is part of the boomerang pattern of the large-scale sea surface temperature structure of ENSO; and it also has its maximum amplitude in the winter hemisphere. The boomerang sea surface temperature anomalies are "upstream" rather than being collocated with the Maritime Continent rainfall. A mechanism has been hypothesised whereby the interannual variability of Maritime Continent rainfall is simply a downstream response to the boomerang sea surface temperature pattern. The validity of this hypothesis will be explored in future studies.

In our earlier study (Haylock and McBride 2001), based on the analysis of rainfall data it was concluded that December-January Indonesian rainfall was inherently unpredictable. This conclusion was based on the lack of large-scale coherence of interannual rainfall anomalies in the region. The results of the current paper would imply that the lack of predictability is confined to the summer hemisphere and that the parts of Indonesia and/or the Maritime Continent north of the equator are predictable at that time of year. Some care should be taken, however, in relating OLR to rainfall. As a check on the strength of the relationship, correlations were calculated between monthly values of OLR and rainfall summed over all rainfall stations (from the Haylock-McBride set) in that OLR grid box. For the months of July-September when rainfall variations are spatially coherent, the correlation between interannual rainfall anomalies and interannual OLR anomalies exceeded 0.5 in magnitude for $72 \%$ of the grid boxes. For JanuaryMarch (when rainfall variations are not spatially coherent), the OLR-rainfall correlations exceeded 0.5 in magnitude for only $15 \%$ of the grid boxes. Thus, the magnitude of the relationship is quite weak at the time of year when the convective activity is greatest.

The association between predictability and coherence also needs to be further explored. For predictability associated with a low-frequency phenomenon such as ENSO, the association is intuitively obvious. However, it is an idea with important implications. For example, in a region of the world where there is no large-scale coherence of anomalies, it discourages the search for further large-scale predictors in the instance where the
SOI-rainfall relationship is weak. It also provides some upper limit on the proportion of variance associated with the predictable signal.

The concept is still in a primitive form. In this paper the coherence was related simply to the spatial structure of the first unrotated EOF. As shown for rainfall data, however, in Haylock and McBride (2001), there can be localized but spatially coherent behavior in several of the higher-order EOFs; and clearly the size of the domain will have some effect on the number of leading EOFs required to capture the dominant large-scale coherence. The EOF calculations of Fig. 1 have been carried out over a number of different domains of varying size and with various central locations, as a check on the statements in section 2. In particular it was verified that the high loadings remained over the Maritime Continent during the northern summer.

Finally, the results of this short study have implications for understanding the mechanisms by which ENSO governs rainfall. In particular, it has been inferred that Indonesian rainfall variations may be a direct downstream response to sea surface temperature anomalies in the close-by region of the "boomerang pattern." This is rather than the variations being a remote response to equatorial central Pacific sea surface temperature anomalies (via the Walker circulation). An important area of further work is to understand how the boomerang sea surface temperature anomaly pattern itself develops, presumably in response to the evolution of ENSO-associated sea surface temperature anomalies in the equatorial central and eastern Pacific.

Acknowledgments. This research is partially supported by the Australian Centre for International Agricultural Research Project LWR2/96/215. Comments from Harry Hendon, Wasyl Drosdowsky, George Kiladis, and an anonymous referee are greatly appreciated.

\section{REFERENCES}

Allan, R. J., N. Nicholls, P. D. Jones, and I. J. Butterworth, 1991: A further extension of the Tahiti-Darwin SOI, early ENSO events and Darwin pressure. J. Climate, 4, 743-749.

Drosdowsky, W., and L. E. Chambers, 2001: Near-global sea surface temperature anomalies as predictors of Australian seasonal rainfall. J. Climate, 14, 1677-1687.

Gill, A. E., 1980: Some simple solutions for heat induced tropical circulation. Quart. J. Roy. Meteor. Soc., 106, 447-462.

Gruber, A., and A. F. Krueger, 1984: The status of the NOAA outgoing longwave radiation data set. Bull. Amer. Meteor. Soc., 65, 958962 .

Hastenrath, S., 1987: Predictability of Java monsoon rainfall anomalies: A case study. J. Climate Appl. Meteor., 26, 133-141.

Haylock, M., and J. McBride, 2001: Spatial coherence and predictability of Indonesian wet season rainfall. J. Climate, 14, 38823887.

Heddinghaus, T. R., and A. F. Krueger, 1981: Annual and interannual variations in outgoing longwave radiation over the tropics. Mon. Wea. Rev., 109, 1208-1218.

Hsiung, J., and R. E. Newell, 1983: The principal nonseasonal modes of global sea surface temperature. J. Phys. Oceanogr., 13, 19571967. 
Kiladis, G. N., and H. F. Diaz, 1989: Global climatic anomalies associated with extremes in the Southern Oscillation. J. Climate, 2, 1069-1090.

Kirono, D. G. C., N. J. Tapper, and J. L. McBride, 1999: Documenting Indonesian rainfall in the 1997/1998 El Niño event. Phys. Geogr., 20, 422-435.

Kirtman, B. P., and J. Shukla, 2000: Influence of the Indian summer monsoon on ENSO. Quart. J. Roy. Meteor. Soc., 126, 213-239.

Klein, S. A., B. J. Soden, and N.-C. Lau, 1999: Remote sea surface temperature variations during ENSO: Evidence for a tropical atmospheric bridge. J. Climate, 12, 917-932.

Lau, K.-M., and P. H. Chan, 1983a: Short-term climate variability and atmospheric teleconnections from satellite-observed outgoing longwave radiation. Part I: Simultaneous relationships. $J$. Atmos. Sci, 40, 2735-2750.

— spheric teleconnections from satellite-observed outgoing longwave radiation. Part II: Lagged correlations. J. Atmos. Sci., 40, 2751-2767.

- , and H. T. Wu, 2001: Principal modes of rainfall-SST variability of the Asian summer monsoon: A reassessment of the monsoonENSO relationship. J. Climate, 14, 2880-2895.

Lau, N.-C., and M. J. Nath, 1996: The role of the atmospheric bridge in linking tropical Pacific ENSO events to extratropical SST anomalies. J. Climate, 9, 2036-2057.

Lawrence, D. M., and P. J. Webster, 2001: Interannual variations of the intraseasonal oscillation in the South Asian summer monsoon region. J. Climate, 14, 2910-2922.

McBride, J. L., 1998: Indonesia, Papua New Guinea, and tropical Australia. The Southern Hemisphere summer monsoon. Meteorology of the Southern Hemisphere, Meteor. Monogr., No. 49, Amer. Meteor. Soc., 89-99.

—_ , and N. Nicholls, 1983: Seasonal relationships between Australian rainfall and the Southern Oscillation. Mon. Wea. Rev., 111, 1998-2004.

Meehl, G. A., 1987: The annual cycle and interannual variability in the tropical Pacific and Indian Ocean regions. Mon. Wea. Rev., 115, 27-50.

Nicholls, N., 1981: Air-sea interaction and the possibility of longrange weather prediction in the Indonesian Archipelago. Mon. Wea. Rev., 109, 2435-2443.

Parker, D. E., C. K. Folland, A. C. Bevan, M. N. Ward, M. Jackson, and K. Maskell, 1995: Marine surface data for analysis of climatic fluctuations on interannual-to-century time scales. Natural Climate Variability on Decadal-to-Century Time Scales, National Research Council, 241-252.

Rasmusson, E. M., and T. H. Carpenter, 1982: Variations in tropical sea surface temperature and surface wind fields associated with the Southern Oscillation/El Niño. Mon. Wea. Rev., 110, 354384.

Ropelewski, C. F., and M. S. Halpert, 1987: Global and regional scale precipitation patterns associated with the El Niño/Southern Oscillation. Mon. Wea. Rev., 115, 1606-1626.

Saji, N. H., B. N. Goswami, P. N. Vinayachandran, and T. Yamagata, 1999: A dipole mode in the tropical Indian Ocean. Nature, 401 360-363.

Simmons, A. J., J. M. Wallace, and G. W. Branstator, 1983: Barotropic wave propagation and instability, and atmospheric teleconnection patterns. J. Atmos. Sci., 40, 1363-1392.

Ting, M., and P. D. Sardeshmukh, 1993: Factors determining the extratropical response to equatorial diabatic heating anomalies. J. Atmos. Sci., 50, 907-918.

Weare, B. C., A. R. Navato, and R. E. Newell, 1976: Empirical orthogonal analysis of Pacific sea surface temperatures. J. Phys Oceanogr., 6, 671-678.

Webster, P. J., 1981: Mechanisms determining the atmospheric response to sea surface anomalies. J. Atmos. Sci., 38, 554-571.

—_, A. M. Moore, J. P. Loschnigg, and R. R. Leben, 1999: Coupled ocean-atmosphere dynamics in the Indian Ocean during 199798. Nature, 401, 356-360.

Zebiak, S. E., 1982: A simple atmospheric model of relevance to El Niño. J. Atmos. Sci., 39, 2017-2027. 
Copyright $\odot 2003$ EBSCO Publishing 